\title{
Expression of P-glycoprotein and Metallothionein in Gastrointestinal Stromal Tumor and Leiomyosarcomas. Clinical Implications
}

\author{
Sofia PÉREZ-GUTIÉRREZ, ${ }^{1}$ Ricardo GONZÁLEZ-CÁMPORA, ${ }^{2}$ Joaquín AMÉRIGO-NAVARRO, ${ }^{3}$ \\ Antonio BEATO-MORENO, ${ }^{4}$ María SÁNCHEZ-LEÓN, ${ }^{2}$ María Jesús PAREJA MEGÍA, ${ }^{2}$ \\ Juan Antonio VIRIZUELA-ECHABURU ${ }^{5}$ Antonio LÓPEZ-BELTRÁN ${ }^{6}$
}

\begin{abstract}
${ }^{1}$ Pathology Service, Juan Ramón Jiménez Hospital, Huelva; ${ }^{2}$ Department of Pathology, Virgen Macarena University Hospital and University of Seville Medical School, Seville; ${ }^{3}$ Pathology Service, Hospital Torrecárdenas, Almería;

${ }^{4}$ Department of Statistic and Operations Research, University of Seville, Seville; ${ }^{5}$ Oncology Service, Virgen Macarena University Hospital, Seville; ${ }^{6}$ Department of Pathology, Reina Sofia University Hospital and Córdoba University Medical School, Córdoba, Spain
\end{abstract}

We investigated the expression of P-glycoprotein (P-GP) and metallothionein (MT) in a series of 92 GIST and 14 gastrointestinal leiomyosarcomas (GILMS) with the purpose to expand our knowledge on the biological bases of GIST chemo-resistance and to ascertain their significance in patients' prognosis. P-GP expression was more frequent in GIST than in GI-LMS $(83.7 \%$ vs. $21.4 \%$, p $<0.001)$, with no difference between low- and high-risk GIST $(\mathrm{p}=1.000)$ or low- and high-grade GI-LMS $(\mathrm{p}=0.538)$. P-GP expression was unrelated to anatomic location (gastric vs. intestinal) in GIST (39/45 vs. 35/43, $\mathrm{p}=0.770)$ and in GI-LMS (0/2 vs. $2 / 6, \mathrm{p}=1.000)$. MT expression was non-significantly higher in GI-LMS than in GIST $(35.7 \%$ vs. $14.1 \%$, $p=0.060)$, with no difference between low- and high-risk GIST $(\mathrm{p}=1.000)$ or low- and high-grade GI-LMS ( $\mathrm{p}=1.000)$. MT expression was unrelated to the anatomic location (gastric vs. intestinal) in GIST (7/45 vs. 6/43) and GI-LMS $(0 / 2$ vs. $1 / 6) \quad(p=1.000$ and $p=0.1000$, respectively). Overall tumor-specific survival $(p<$ $0.001)$ and disease-free survival $(p<0.001)$ were different in GIST as compared with GI-LMS, and the number of events was higher in GI-LMS. When the survival analysis took into consideration P-GP or MT expression, the overall survival in GIST was influenced by the expression of MT $(p=0.021)$ but not by that of P-GP $(p=0.638)$. However, in GI-LMS, P-GP expression influenced disease-free survival $(p=0.050)$; in addition, it is important to recognize the limited value of these results because of the low number of cases involved in the study. Differential expression of P-GP and MT might explain the known variability in response to systemic chemotherapy in these tumors. Detection of P-GP and MT seems to add certain prognostic value in GIST (MT) or GI-LMS (P-GP). (Pathology Oncology Research Vol 13, No 3, 203-208)

Key words: gastrointestinal stromal tumors, GIST, leiomyosarcomas, P-glycoprotein, metallothionein

\section{Introduction}

Gastrointestinal stromal tumors (GIST) are neoplasms originating from interstitial cells of Cajal (ICC) or their precursor, ${ }^{9}$ and account for $1-3 \%$ of malignancies in the

Received: Oct 17, 2006; accepted: July 10, 2007

Correspondence: Prof. Ricardo GONZÁLEZ-CÁMPORA, Department of Pathology, Virgen Macarena University Hospital, Avda, Dr. Fedriani s/n, 41009 Seville, Spain. Tel: 34 955008556, Fax: 34 954371284, e-mail: rcampora@us.es gastrointestinal tract (GI). ${ }^{1}$ Until 1998, when Hirota et $\mathrm{al}^{10}$ and Kindblom et al ${ }^{13}$ demonstrated that GIST are a special group of GI mesenchymal tumors characterized by CD117 expression and frequent KIT mutation, most of these neoplasms were considered leiomyosarcomas (LMS), were treated with chemotherapy and had low response rate. This chemo-response contrasted with those reported in LMS in other locations where the response rate was significantly higher. ${ }^{3}$ The biological bases of chemo-sensitivity of these neoplasms remain uncertain, but it is well known that anthracyclines and cisplatin, drugs used in 
Table 1. Primary antibodies used in the assessment of GIST and GI-LMS

\begin{tabular}{lllll}
\hline Primary antibodies & Clone & Working dilution & Source & Controls \\
\hline CD117 (c-kit) & 104D2 & $1: 50$ & Dako & mast cells \\
CD34 & AM236-5M & prediluted & Biogenex & endothelial cells \\
Smooth muscle actin & 1A4 & prediluted & Dako & muscle layer from intestinal wall \\
Desmin & D33 & prediluted & Dako & muscle layer from intestinal wall \\
S-100 protein & AM058-5M & prediluted & Biogenex & Schwann cells from normal intestinal wall \\
Metallothionein & E9 & $1: 200$ & Dako & mammary gland \\
P170/P-glycoprotein & C494 & prediluted & LabVision Co & cortical adrenal gland \\
\multicolumn{1}{l}{ MDR Ab-5 } & & & & \\
\hline
\end{tabular}

advanced LMS and GIST, are the substrate for multi-drug resistance (MDR) proteins ${ }^{15}$ and metallothionein $(\mathrm{MT}),{ }^{12}$ respectively.

On the other hand, since the introduction of therapeutic targeting with tyrosine kinase inhibitor imatinib (Gleevec, Novartis Pharma AG, Basel, Switzerland) for GIST treatment, ${ }^{11}$ special effort has been made to separate this tumors from their mimicry, and specially from LMS, which has very low-to-null response to imatinib, ${ }^{14}$ which is in vitro also a substrate for MDR.?

Our purpose is to establish whether or not the expression of the MDR proteins, particularly P-glycoprotein (PGP) and metallothionein (MT) may correlate to the patients' outcome and if additionally might assist to explain the observed differences in response to systemic chemotherapy in a series of GIST and gastrointestinal LMS (GI-LMS).

\section{Material and methods}

Patients

The study group included 106 patients with GIST $(n=92)$ or GI-LMS $(n=14)$ retrieved from 3 hospitals in Southern Spain. Patients' follow-up was available in 77 cases (64 GIST and 12 GI-LMS) and was calculated as the number of months from the date of the surgical procedure to the last visit or death. The overall tumor-specific survival was defined as the time between diagnosis and the patient's death. The disease-free survival was defined as the time between the diagnosis and the first relapse or the appearance of metastases. Cancer-related death was defined as that caused by the tumor.

\section{Pathology}

GIST tumors were grouped into two prognostic categories resulting from grouping the four categories originally proposed by Fletcher et $\mathrm{al}^{5}$ with the addition of an "overtly malignant group": ${ }^{16}$ low (65: 3 very low risk, 42 low risk, 20 intermedium risk) and high (27: 26 high risk, 1 overtly malignant with metastasis). LMS $^{20}$ were graded as low $(n=8)$ and high $(n=6)$. In order to determine if the expression of P-GP or MT in GI-LMS is region-dependent, an additional group of 26 non-GI LMS from the uterus (12), retroperitoneum (8), skin and soft tissues (6) was evaluated. Additional immunohistochemical markers (CD117, CD34, smooth muscle actin, desmin and S-100) were included to confirm pathologic diagnosis in GIST and LMS.

Available hematoxylin and eosin stained slides were reassessed by three pathologists (SGP, RGC, ALB) blind to the clinical status. For immunohistochemistry, a representative paraffin block from each tumor, selected based on the amount of tumor present, was serially cut at $4 \mu \mathrm{m}$ thick, deparaffinized in xylene, rehydrated in graded ethanol and washed for $5 \mathrm{~min}$ with phosphate-buffered saline. For antigen retrieval, the sections were boiled immersed in $10 \mathrm{mM}$ citrate buffer (pH 6.0). To avoid nonspecific CD117 immunostaining, we followed the manufacturer recommendations and the procedure included with Target Retrieval Solution (S1699, Dako, Glostrup, Denmark). Endogenous peroxidase was blocked by incubation of the slides for 30 minutes with $3 \%$ hydrogen peroxide in methanol. Sections were then incubated with the primary mouse monoclonal antibodies at room temperature (Table 1).

Immunohistochemistry was performed using the highly sensitive polymer-based system (EnVision, Dako) 30 min at room temperature with diaminobenzidine chromogen substrate solution $(0.6 \mathrm{mg} / \mathrm{ml}$ in Tris-buffered saline, $\mathrm{pH} 7.6$, with $12 \mathrm{ml} 30 \%$ hydrogen peroxide). Sections were counterstained with Mayer's hematoxylin, dehydrated and mounted following standard procedure. Three pathologists (SGP, RGC, ALB) independently evaluated all immunostainings in a blinded fashion. The following staining patterns were considered: CD117, cytoplasmic and/or membrane; CD34, membrane; smooth muscle actin and desmin, cytoplasmic; S-100, cytoplasmic and nuclear; P-GP, membrane and sometimes also cytoplasmic; MT, cytoplasmic and nuclear. Cases with less than $10 \%$ positive cells were considered negative. 
Statistical analysis

Bivariate analysis to compare prognostic categories and the expression of P-GP and MT were undertaken by Fisher test and chi-square analysis. Univariate survival analysis for P-GP and MT expressions was conducted using Kaplan-Meier method and differences among groups were tested by log-rank test. All statistical analyses were performed using the SPSS for Windows Software (SPSS Inc, Chicago, IL, USA). A p-value of less than 0.05 was considered as significant.

\section{Results}

Table 2 shows relevant comparative data on GIST and GILMS cases included in this study. Plasma membrane and sometimes cytoplasmic expression of P-GP was observed in GIST $(83.7 \%)$ and GI-LMS $(21.4 \%)$ $(\mathrm{p}<0.001)$ (Fig. 1a,b). No differences were found between lowand high-risk GIST $(\mathrm{p}=1.000)$ or low- and high-grade GI-LMS $(\mathrm{p}=0.538)$. In the same way, PGP expression was unrelated to anatomic location (gastric vs. intestinal) in GIST (39/45 vs. $35 / 43, \mathrm{p}=0.770$ ), in both low$(\mathrm{p}=0.447)$ and high-risk groups $(\mathrm{p}=0.355)$, and in GI-LMS $(0 / 2$ vs. $2 / 7, \mathrm{p}=1.000$ ).

MT was detected in scattered tumor cells in the cytoplasm and occasionally in the nucleus (Fig. $1 c, d$ ) in GI-LMS $(35.7 \%$ ) and GIST $(14.1 \%) \quad(\mathrm{p}=0.060)$. No differences were observed between low- and high-risk GIST $(\mathrm{p}=1.000)$ or low- and high-grade GI-LMS $(\mathrm{p}=1.000)$. No association was found between MT expression and anatomical location (gastric vs. intestinal) in GIST (7/45 vs. 6/43) or GILMS (0/2 vs.1/6) (both $\mathrm{p}=1.000)$. Simultaneous P-GP and MT expression was observed in 11/92 GIST and 1/14 GILMS cases $(\mathrm{p}=1.000)$.

Overall tumor-specific survival and disease-free survival were different in GIST as compared with GI-LMS (both $\mathrm{p}<0.001$ ); the number of events was higher in GI-
Table 2. Clinical, pathological data and marker expression in 92 cases of GIST as compared with 14 GI-LMS cases

\begin{tabular}{|c|c|c|}
\hline & GIST (n=92) & GI-LMS $(n=14)$ \\
\hline \multicolumn{3}{|l|}{ Age (years) } \\
\hline Mean & 61.44 & 70.83 \\
\hline Median & 64.00 & 74.50 \\
\hline \multicolumn{3}{|l|}{ Sex } \\
\hline Male & $49(53.3 \%)$ & $4(28.6 \%)$ \\
\hline Female & $43(46.7 \%)$ & $10(71.4 \%)$ \\
\hline \multicolumn{3}{|l|}{ Location } \\
\hline Stomach & $45(48.9 \%)$ & $2(14.3 \%)$ \\
\hline Small bowel & $38(41.3 \%)$ & $5(35.7 \%)$ \\
\hline Large bowel & $5(5.4 \%)$ & $2(14.3 \%)$ \\
\hline Mesentery-omentum & $4(4.3 \%)$ & $5(35.7 \%)$ \\
\hline \multicolumn{3}{|l|}{ Size $(\mathrm{cm})$} \\
\hline Mean & 6.85 & 8.28 \\
\hline Median & 5.00 & 9.00 \\
\hline \multicolumn{3}{|l|}{ Cell type } \\
\hline Spindle & $66(71.7 \%)$ & $14(100 \%)$ \\
\hline Epithelioid & $22(23.9 \%)$ & - \\
\hline Mixed & $4(4.3 \%)$ & - \\
\hline \multicolumn{3}{|l|}{ Risk/grade category } \\
\hline Low & $65(70.7 \%)$ & $8(57.1 \%)$ \\
\hline High & $27(29.3 \%)$ & $6(42.9 \%)$ \\
\hline \multicolumn{3}{|l|}{ Maker immunoreactivity } \\
\hline \multirow[t]{3}{*}{ P-glycoprotein } & $77(83.7 \%)$ & $3(21.4 \%)$ \\
\hline & Low-risk: 58 (89.2\%) & Low-grade: 1 (12.5\%) \\
\hline & High-risk: 19 (70.4\%) & High-grade: $2(33.3 \%)$ \\
\hline \multirow[t]{3}{*}{ Metallothionein } & $13(14.1 \%)$ & $5(35.7 \%)$ \\
\hline & Low-risk: 8 (12.3\%) & Low-grade: 3 (37.5\%) \\
\hline & High-risk: 5 (18.5\%) & High-grade: $2(33.3 \%)$ \\
\hline \multirow{3}{*}{ Clinical follow-up } & $\mathrm{n}=64(69.5 \%)$ & $\mathrm{n}=13(86.6 \%)$ \\
\hline & Low-risk: 43 (67.2\%) & Low-grade: $8(61.5 \%)$ \\
\hline & High-risk: $21(32.8 \%)$ & High-grade: 5 (38.5\%) \\
\hline Mean (months) & 66.48 & 32.08 \\
\hline Median (months) & 36.00 & 23.50 \\
\hline Tumor recurrence & $10(15.6 \%)$ & $4(33.3 \%)$ \\
\hline Metastases & $8(12.5 \%)$ & $6(50 \%)$ \\
\hline Alive with disease & $11(17.2 \%)$ & $2(16.7 \%)$ \\
\hline Alive without disease & $41(64.0 \%)$ & $3(25.0 \%)$ \\
\hline Dead of disease & $8(12.5 \%)$ & $7(58.3 \%)$ \\
\hline Dead of other causes & $4(6.2 \%)$ & $0(0 \%)$ \\
\hline
\end{tabular}

LMS (Table 3). When the study was restricted to highrisk GIST and all GI-LMS, no significant differences were observed in overall or disease-free survival ( $p=0.081$ and $p=0.373$, respectively). When the survival analysis took into consideration P-GP or MT expression, the overall survival in GIST was influenced by the expression of MT ( $\mathrm{p}=0.021)$ but not by P-GP $(\mathrm{p}=0.638)$. On the other hand, P-GP expression significantly influenced disease-free survival in GI-LMS ( $\mathrm{p}=0.050)$ (Table 3 ); however, it is important to recognize the limited value of these results because of the low number of cases involved in the study. No differences were observed 

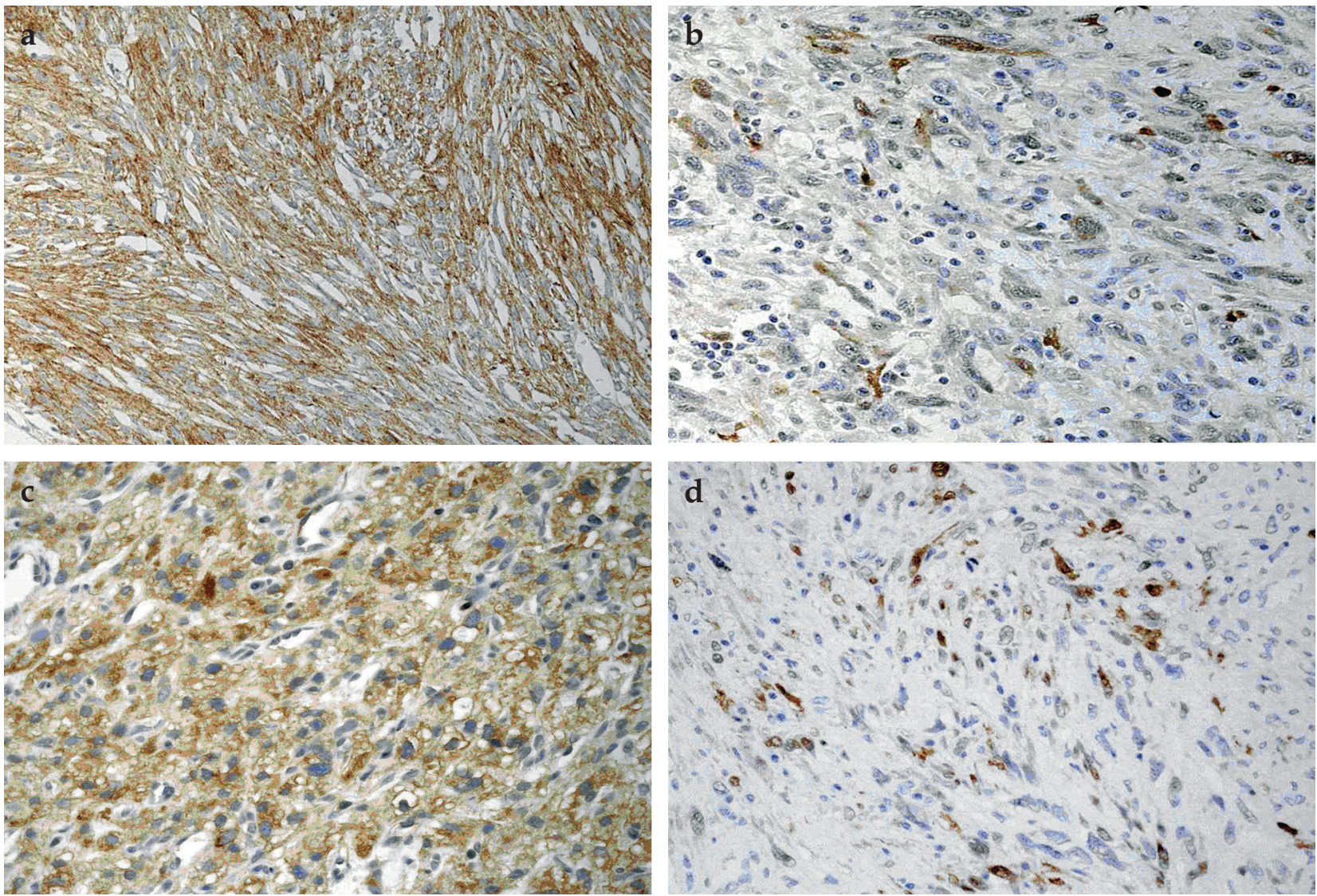

Figure 1. Gastrointestinal stromal tumor. Positive immunoreaction to P-GP, 20x (a) and MT, 40x (b). Gastrointestinal leiomyosarcoma. Positive immunoreaction to P-GP, 40x (c) and MT, 20x (d)

Table 3. Overall and disease-free survival of patients with GIST and GI-LMS according to P-glycoprotein and metallothionein expression

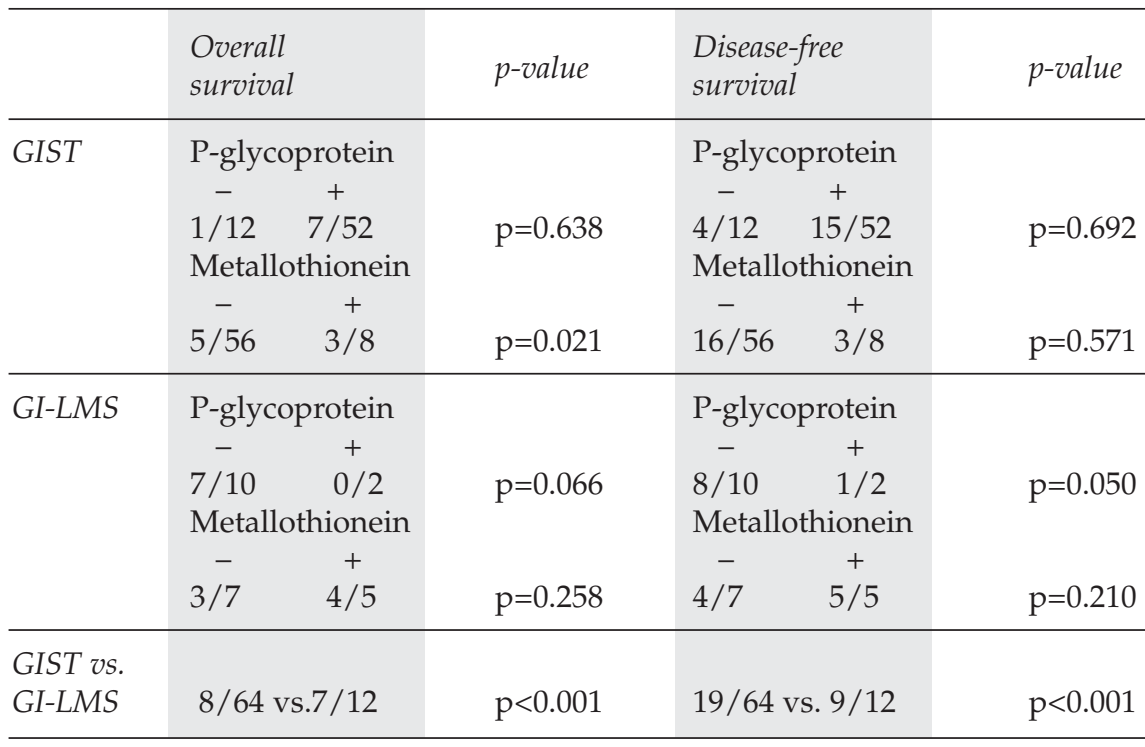

Data are presented as number of events / case number in the groups with negative or positive expression of the markers between GI-LMS and non-GI LMS for P-GP $(\mathrm{p}=0.199)$ or MT expression $(\mathrm{p}=0.979)$.

\section{Discussion}

Several drug resistance proteins have been considered as the source of explaining chemo-sensitivity in malignant tumors. Two of the most extensively studied proteins are P-GP and MT. P-GP is a transmembrane protein, encoded by the MDR 1 gene, which acts as an efflux transporter system for a variety of organic substances, including cytotoxic drugs, like anthracyclines, Vinca alkaloids and epipodophyllotoxins. ${ }^{15}$ MT is a low-molecular-weight cysteinrich enzyme that binds divalent 
metal ions and plays a protective role against anticancer drugs, such as cisplatin. ${ }^{4,12}$ It is well known that GIST is more chemo-resistant than LMS, ${ }^{3,14,18}$ but little is known on the subjacent mechanism. Plaat et $\mathrm{al}^{18}$ studied the expression of P-GP, MRP1 and LRP in 29 patients with soft tissue LMS and 26 patients with a primary malignant GIST, and found that P-GP and MRP1 expressions were significantly higher in GIST than in LMS, and that patients with LMS had a better overall survival and a metastatic pattern different from GIST. More recently, Theou et a ${ }^{19}$ investigated the expression of MDR proteins (P-GP, MRP1 and BCRP) by Western blotting in 21 GIST cases, showing P-GP and MRP1 in $86 \%$ and $62 \%$, respectively, and negativity for BCRP. These authors found significant differences in P-GP expression between gastric and nongastric tumors. In addition, they suggested that MDR proteins do not impair the initial response of the tumor to imatinib, since none of the six patients treated with imatinib was resistant.

In the present series we have found similar results regarding P-GP, showing significant differences between GIST and GI-LMS. On the other hand, GI-LMS had a worse overall $(\mathrm{p}<0.001)$ and disease-free $(\mathrm{p}=0.001)$ survival than GIST, but when only high-risk GIST entered the analysis, no differences were found. This finding, which differs from that reported by Plaat et al, ${ }^{18}$ may be related to Plaat's selection criteria since they included high-risk GIST only, $68 \%$ of which expressed c-kit. In this series we could not confirm the different P-GP expression between gastric and intestinal cases, since $39 / 45$ of gastric and 35/43 of non-gastric neoplasms expressed P-GP. None of our patients were treated with imatinib.

MT expression is known as an adverse prognostic factor in some tumors, including sarcomas ${ }^{2}$ but, as far as we know, this is the first report relating its expression with survival in GIST. We have found no significant differences between GI-LMS (35.7\%) and GIST (14.1\%) ( $\mathrm{p}=0.060)$, but in GIST, MT expression was associated with overall cancer-specific survival ( $\mathrm{p}=0.021)$. Our results in GI-LMS agree with those of Gaumann et $\mathrm{al}^{6}$ where MT expression in LMS was unrelated to the patients' survival.

We did not find any differences in the P-GP and MT expression between GI-LMS and non-GI LMS, a finding that may help to explain that the lower response rate to conventional chemotherapy, observed in previous GILMS series, ${ }^{3}$ could be related to misclassification of tumors rather than their location. Nonetheless, chemoresistance is a complex phenomenon where other drug resistance $^{21}$ and/or anti-apoptotic mechanisms related to KIT or PDGFRA overexpression are implicated. ${ }^{8,17}$ In GIST, imatinib resistance seems to be related to KIT or PDGFRA mutations rather than to MDR proteins systems, since some specific mutations cause a low to null response. $^{8}$
In conclusion, differences in P-GP and MT expression could help to explain the observed response to systemic chemotherapy in GIST and LMS. Immunoexpression of PGP and MT may assist in differentiating GIST and GILMS in selected cases, and seems to and certain prognostic value in GIST (MT) and GI-LMS (P-GP).

\section{References}

1. Berman J, O'Leary TJ: Gastrointestinal stromal tumor workshop. Hum Pathol 32:578-582, 2001.

2. Dziegiel P, Salwa-Zurawska W, Zurawski J, Wojnar A, Zabel M. Prognostic significance of augmented metallothionein (MT) expression correlated with $\mathrm{Ki}-67$ antigen expression in selected soft tissue sarcomas. Histol Histopathol 2: 83-89, 2005.

3. Edmonson JH, Marks RS, Buckner JC, Mahoney MR: Contrast of response to dacarbazine, mitomycin, doxorubicin and cisplatin (DMAP) plus GM-CSF between patients with advanced malignant gastrointestinal stromal tumors and patients with other advanced leiomyosarcomas. Cancer Invest 20:605-612, 2002.

4. Endresen L, Bakka A, Rugstad HE: Increased resistance to chlorambucil in cultured cells with a high concentration of cytoplasmic metallothionein. 43: 2918-2926, 1983.

5. Fletcher CMD, Berman JJ, Corless C, Gorstein F, Lasota J, Longley BJ, Miettinen M, O'Leary TJ, Remotti H, Rubin BP, Shmookler B, Sobin LH, Weiss SW: Diagnosis of gastrointestinal stromal tumors: a consensus approach. Hum Pathol 33: 459-465, 2002.

6. Gaumann A, Tews DS, Mentzel T, Petrow PK, Mayer E, Otto M, Kirkpatrick CJ, Kriegsmann J: Expression of drug resistance related proteins in sarcomas of the pulmonary artery and poorly differentiated leiomyosarcomas of other origin. Virchows Arch 442: 529-537, 2003.

7. Hegedus T, Orfi L, Seprodi A, Varadi A, Sarkadi B, Keri G: Interaction of tyrosine kinase inhibitors with the human multidrug transporter proteins, MDR1 and MRP1. Biochim Biophys Acta 1587: 318-325, 2002.

8. Heinrich $M C$, Corless $C L$, Demetri GD, Blanke $C D$, von Mehren M, Joensuu H, McGreevey LS, Chen CJ, Van den Abbeele AD, Druker BJ, Kiese B, Eisenberg B, Roberts PJ, Singer S, Fletcher CD, Silberman S, Dimitrijevic S, Fletcher JA: Kinase mutations and imatinib response in patients with metastatic gastrointestinal stromal tumors. J Clin Oncol 21:4342-4349, 2003.

9. Hirota S, Isozaki $K$ : Pathology of gastrointestinal stromal tumors. Pathol Int 56:1-9, 2006.

10. Hirota S, Isozaki K, Moriyama Y, Hashimoto K, Nishida T, Ishiguro S, Kawano K, Hanada M, Kurata A, Takeda M, Muhammad Tunio G, Matsuzawa Y, Kanakura Y, Shinomura Y, Kitamura Y: Gain-of-function mutations of c-kit in human gastrointestinal stromal tumors. Science 279: 577-580, 1998.

11. Joensuu H, Roberts PJ, Sarlomo-Rikala M Andersson LC, Tervahartiala $P$, Tuveson D, Silberman $S$, Capdeville R, Dimitrijevic $S$, Druker B, Demetri GD: Effect of the tyrosine kinase inhibitor STI571 in a patient with metastatic gastrointestinal stromal tumors. N Engl J Med 344:1052-1056, 2001.

12. Kagi JHR: Overview of metallothionein. Methods Enzymol 205: 613-626, 1991.

13. Kindblom LG, Remotti HE, Aldenborg F, Meis-Kindblom JM: Gastrointestinal pacemaker cell tumor (GIPACT): gastrointestinal stromal tumors show phenotypic characteristics of the interstitial cells of Cajal. Am J Pathol 152:1259-1269, 1998. 
14. Lehnert T: Gastrointestinal sarcoma (GIST) - a review of surgical management. Ann Chir Gynecol 87: 297-305, 1998.

15. Merino V, Relevance of multidrug resistance proteins on the clinical efficacy of cancer therapy. 1: 203-212, 2004.

16. Nilsson B, Bumming P, Meis-Kindblom JM, Oden A, Dortok A, Gustavsson B, Sablinska K, Kindblom LG: Gastrointestinal stromal tumors: the incidence, prevalence, clinical course, and prognostication in the preimatinib mesylate era - a population-based study in western Sweden. Cancer 103: 821-829, 2005.

17. Ning ZQ, Li J, Arceci RJ: Activating mutation of c-kit at codon 816 confers drug resistance in human leukemia cells. Leuk Lymphoma. 41: 513-522, 2001.

18. Plaat BEC, Hollema H, Willemina MM: Soft tissue leiomyosarcomas and malignant gastrointestinal stromal tumors: differ- ences in clinical outcome and expression of multidrug resistance proteins. J Clin Oncol 18: 3211-3220, 2000.

19. Theou N, Gil S, Devocelle A Julie C,Lavergne-Slove A, Beauchet A, Callard P, Farinotti R, Le Cesne A, Lemoine A, Faivre-Bon homme L, Emile JF: Multidrug resistance proteins in gastrointestinal stromal tumors: site-dependent expression and initia response to imatinib. Clin Cancer Res 11: 7593-7598, 2005.

20. Weiss SW, Goldblum JR: Enzinger and Weiss's soft tissue tumors, $4^{\text {th }}$ ed., Mosby, St. Louis, 2001.

21. Zwelling A, Slovak ML, Doroshow JH, Hinds M, Chan D, Parker E, Mayes J, Sie KL, Meltzer PS, Trent JM: HT1080/DR4: A P-Glycoprotein-negative human fibrosarcoma cell line exhibiting resistance to topoisomerase II-reactive drugs despite the presence of a drug sensitive topoisomerase II. J Natl Cancer Inst 82: 1553-1561, 1990 